\title{
VALORAÇÃO MONETÁRIA DA ARBORIZAÇÃO URBANA BASEADA NA MAGNITUDE DA COPA EM PIRACICABA/SP/BRASIL
}

Flávio Henrique Mendes

\section{RESUMO}

A arborização urbana proporciona importantes serviços ecossistêmicos, porém, cada vez mais ela compete pelo espaço com grandes superfícies cinzentas, o que a pode tornar um elemento secundário no planejamento das cidades. A valoração monetária das árvores urbanas aparece, então, como mais uma alternativa capaz de mostrar a relevância desses seres vivos. Existem diversos métodos que realizam este cálculo, entretanto, são complexos e não estão ao alcance da população, que almeja melhores condições climáticas. O objetivo desta pesquisa foi desenvolver um método simplificado de valoração baseado na relação entre a área da copa, o Índice de Área Foliar (IAF) e um parâmetro médio $\mathrm{R} \$ / \mathrm{m}^{2}$ de copa encontrado na literatura, ou seja, na magnitude da copa, uma vez que a maior parte dos serviços ecossistêmicos provém dela. O IAF pode ser estimado por meio de lentes olho de peixe a um preço razoável (menos que $\mathrm{R} \$ 25,00$ ), enquanto que a área de copa medida in loco (ou calibrada no passo). O presente estudo foi realizado em Piracicaba/SP/Brasil, na qual as 60.146 árvores urbanas podem retornar aproximadamente $\mathrm{R} \$ 41$ milhões (USD 8,2 milhões) por ano em serviços ecossistêmicos. Investigações como esta, as chamadas Soluções baseadas na Natureza (SbN), poderão auxiliar no planejamento, gestão e formulação de políticas públicas, e até como pagamento por serviços ambientais (descontos em IPTU) aos moradores que possuam árvores em frente à sua casa.

\section{Palavras-chave}

Índice de Área Foliar; Resiliência Urbana; Serviços Ecossistêmicos; Infraestrutura Verde; Soluções Baseadas na Natureza. 


\section{VALORACIÓN MONETARIA DEL ARBOLADO URBANO SOBRE LA BASE DE LA MAGNITUD DE LA COPA EN PIRACICABA/SP/BRASIL}

Flávio Henrique Mendes

Hugo Romero

António Manuel Saraiva Lopes

Maria de Assunção Ribeiro Franco

Demóstenes Ferreira da Silva Filho

\section{RESUMEN}

El arbolado urbano proporciona importantes servicios ecosistémicos, sin embargo, compite cada vez más por el espacio con grandes superficies grises, lo que puede convertirlo en un elemento secundario en la planificación urbana. La valoración monetaria de los árboles urbanos aparece, entonces, como otra alternativa capaz de mostrar la relevancia de estos seres vivos. Existen varios métodos que realizan este cálculo, pero son complejos y no están al alcance de la población, que busca mejores condiciones climáticas. El objetivo de esta investigación fue desarrollar un método de valoración simplificado basado en la relación entre el área de copa, el Índice de Área Foliar (IAF) y un parámetro promedio de BRL/ $\mathrm{m}^{2}$ de copa encontrado en la literatura, o sea, en la magnitud de la copa, ya que la mayoría de los servicios ecosistémicos provienen de ella. El IAF se puede estimar usando lentes de ojo de pez a un precio razonable (menos de BRL 25,00), mientras que el área del dosel se mide in loco (o calibrado en paso). El presente estudio se realizó en Piracicaba/SP/Brasil, en el que los 60.146 árboles urbanos pueden devolver aproximadamente BRL 41 millones (USD 8,2 millones) por año en servicios ecosistémicos. Estimaciones como esta, llamadas Soluciones basadas en la Naturaleza (SbN), pueden ayudar en la planificación, gestión y formulación de políticas públicas, e incluso como pago por servicios ambientales (descuentos en el Impuesto Predial e Territorial Urbano) a los residentes que tienen árboles frente a su casa.

\section{Palabras clave:}

Índice de área foliar; Resiliencia urbana; Servicios ecosistémicos; infraestructura verde; Soluciones basadas en la Naturaleza. 


\title{
MONETARY VALUATION OF URBAN FORESTRY BASED ON THE MAGNITUDE OF THE CROWN IN PIRACICABA/SP/BRAZIL
}

Flávio Henrique Mendes

Hugo Romero

António Manuel Saraiva Lopes

Maria de Assunção Ribeiro Franco

Demóstenes Ferreira da Silva Filho

\begin{abstract}
Urban forestry provides important ecosystem services, however, it increasingly competes for space with large gray surfaces, which can make it a secondary element in the city planning. The monetary valuation of urban trees appears, then, as one more alternative capable of showing the relevance of these living beings. There are several methods that perform this calculation, however, they are complex and are not within reach of the population, which aims for better weather conditions. The objective of this research was to develop a simplified method of valuation based on the relationship between the area of the crown, the Leaf Area Index (LAl) and an average parameter $B R L / m^{2}$ of crown found in the literature, that is, on the magnitude of the crown, since most ecosystem services come from it. The LAI can be estimated using fisheye lenses at a reasonable price (less than BRL 25.00), while the canopy area can be measured in loco (or ground truth calibration). The present study was carried out in Piracicaba/SP/Brazil, in which the 60,146 urban trees can return approximately BRL 41 million (USD 8.2 million) per year in ecosystem services. Investigations like this, the so-called Nature-based Solutions (NbS), may assist in urban planning, management and formulation of public policies, and even as payment for environmental services (Urban Property and Land Tax discounts) to residents who have trees in front of their house.
\end{abstract}

\section{Keywords}

Leaf Area Index; Urban Resilience; Ecosystem Services; Green Infrastructure; Nature-Based Solutions. 


\section{INTRODUÇÃO}

Os serviços ecossistêmicos (também conhecidos como serviços ambientais) correspondem aos benefícios da natureza obtidos pela sociedade, de modo direto ou indireto, visando a sustentabilidade da vida no planeta e o combate às Mudanças Climáticas. Floresta Urbana, Serviços Ecossistêmicos (desde 2006), Infraestrutura Verde (desde 2007) e Soluções baseadas na Natureza (desde 2015) são alguns dos termos utilizados nas pesquisas científicas sobre esta temática. Embora utilizados muitas vezes como sinônimos, são conceitos distintos, que derivam da Floresta Urbana.

A Infraestrutura Verde remete ao padrão espacial e conectividade da vegetação urbana com o ambiente natural, os Serviços Ecossistêmicos diz respeito às funções naturais em que se beneficiam natureza e humanos, e as Soluções baseadas na Natureza, por sua vez, às aplicações para resolver problemas ambientais urbanos e desafios sociais, políticos e ecológicos (ESCOBEDO et al., 2019). Serviços ecossistêmicos e Soluções baseadas na Natureza, inclusive, são os termos utilizados no relatórios mais recentes da World Wildlife Fund (WWF, 2020).

A vegetação urbana é responsável pela regulação dos ciclos climáticos, hidrológicos e da biodiversidade nas cidades, além de oferecer tranquilidade, espaços públicos e locais de lazer que elevam os padrões de vida, aumentam o conforto e contribuem para a coesão social dos habitantes. A existência de bairros vulneráveis e sem vegetação suficiente pode ser um sinal de injustiça ambiental em muitas cidades latino-americanas (MENDES; ROMERO; SILVA FILHO, 2020; ROMERO; MENDES, 2021).

É desejável que as áreas verdes no interior das cidades e seus serviços ecossistêmicos sejam distribuídos de forma que favoreçam também os setores mais vulneráveis, e não como ocorrem atualmente, concentrando-se em áreas ricas, na qual bens e serviços são "comodificados" pelo poder público, visando a especulação imobiliária (ROMERO; MENDES, 2020).

No ambiente urbano, por exemplo, a cidade de Vancouver, no Canadá, conseguiu se tornar a mais sustentável do mundo, com expressivos investimentos em áreas verdes e arborização urbana, por meio de uma política pública adotada em julho de 2011, denominada Greenest City 2020 Action Plan (GCAP), a qual aproximou a acessibilidade de quase todos os seus habitantes à alguma área verde em menos de 10 minutos a pé, sendo o grande destaque o Stanley Park, o maior parque urbano do país, com aproximadamente 400 ha de tamanho, superando em mais de seis vezes o Central Park dos EUA (CITY OF VANCOUVER, 2012; AFFOLDERBACH; SCHULZ, 2017). 
No Brasil, um dos maiores exemplos nessa questão é a cidade de Maringá, no estado do Paraná, a qual possui entre duas a três árvores urbanas por habitante (MENDES, 2021), mais do que o dobro sugerido pela Sociedade Brasileira da Arborização Urbana (SBAU, 1996), de no mínimo uma árvore para cada cinco habitantes, ou seja, o equivalente a $15 \mathrm{~m}^{2}$ de cobertura arbórea por habitante. Aqui cabe uma ressalva: há artigos científicos que utilizam a Organização das Nações Unidas (ONU) como referência, preconizando $12 \mathrm{~m}^{2} /$ hab. , porém, nenhum deles aponta onde encontrar esse valor, convergindo a uma bola de neve (citações e apuds equivocados), o que torna essa referência obscura, conforme discutido por Macedo (1995).

Em termos qualiquantitativos, Mendes (2021) criou quatro faixas para auxiliar as prefeituras quanto aos primeiros passos na gestão da arborização urbana, sendo elas Muito Crítico, Crítico, Parcialmente Satisfatório e Muito Satisfatório, a depender da quantidade de árvores a cada 1000 habitantes. Em complementação, Oliveira e Gandara (2021) romperam o paradigma da correlação linear entre vegetação e renda, encontrando uma relação semelhante a uma parábola com concavidade para cima, ou seja, as classes baixa e alta são as que apresentam maior permeabilidade do solo em suas propriedades, ao passo que a classe média costuma cimentar a maior parte de suas áreas, mas há uma diferença marcante entre as classes baixa e alta: na primeira há o predomínio de plantas medicinais, alimentícias e árvores frutíferas, enquanto que a segunda a função principal é ornamental e paisagística.

Tendo em vista a necessidade de aproximar a teoria da prática, isto é, a quantificação dos benefícios ecossistêmicos, na década de 1960 começaram a surgir os primeiros modelos matemáticos para valoração da arborização urbana (SILVA FILHO; TOSETTI, 2010). Os diversos modelos existentes levam em consideração vários fatores, tais como características dendrométricas (altura, diâmetro à altura do peito DAP, área da copa, área foliar), diversidade de espécies (abundância, frequência), condição fitossanitária (ruim, regular, boa), condições ambientais (remoção da poluição do ar, sequestro de carbono, efeitos de energia de construção) e valores de propriedade (cultural, histórico, sentimental), sendo os métodos mais comuns os de valoração hedônica (baseiam-se na valorização do imóvel), contingente (baseiam-se na disposição em pagamentos e recebimentos) e fórmula (baseiam-se nos custos de implantação e manutenção) (VIANA et al., 2012).

Em 2006, foi desenvolvido pelo USDA Forest Service o i-Tree, um pacote (suite) gratuito de ferramentas para análise e gestão da arborização urbana e rural, baseado no modelo Urban Forest Effects (UFORE), quantificando os serviços ecossistêmicos proporcionados pelas árvores, sendo os pacotes i-Tree Streets e i-Tree ECO os mais recomendados, respectivamente, para a arborização viária e a flores- 
ta urbana (I-TREE, 2020), cujos cálculos podem ser verificados em Nowak et al. (2008). Os próprios autores apresentam como vantagens as medições in loco e a revisão dos dados por pares, o que traz maior fidelidade aos resultados da simulação, mas também discutem que as dificuldades na obtenção das variáveis em campo e o valor estrutural (diferentes custos municipais no manejo e estimativa do custo da terra) podem representar uma limitação, a qual tenta ser ajustada pelo algoritmo do modelo.

Utilizando esta metodologia do i-Tree, em Hutto/Texas (EUA), cidade situada a 200 m acima do nível do mar, clima Cfa (quente e temperado), segundo a classificação proposta por Köppen-Geiger, com quase 1000 mm de pluviosidade anual, Hilde e Paterson (2014) verificaram que os principais benefícios ecossistêmicos foram o aumento no valor da propriedade / estética (47\%), a interceptação da água da chuva (34\%) e a economia de energia elétrica (14\%), totalizando USD $635 \mathrm{mil}$ (BRL 3,2 milhões) / ano com um inventário amostral de 5\% das árvores de arruamento. Considerando a estimativa de 129.300 árvores, resulta num benefício líquido (descontando os custos de manutenção) anual aproximado de USD 100 (BRL 500) por árvore.

Na mesma linha, Wang et al. (2018), em Dalian (China), cidade ao nível do mar, de clima Cwa (subtropical, com $650 \mathrm{~mm}$ de pluviosidade anual), encontraram economia de energia e aumento no valor da propriedade como os principais serviços, numa relação custo-benefício de 1:3,2, gerando um benefício líquido anual estimado em USD 59 (BRL 295) por árvore, os quais variaram entre USD 44 (BRL 220) (árvore de pequeno porte) e USD 140 (BRL 700) (grande porte), parecido com os valores discutidos por McPherson, van Doorn e Goede (2016) para o estado da Califórnia (EUA), com um retorno de 1:5,8, ou seja, aproximadamente USD 92 (BRL 460) por árvore.

Em Londres (UK), os serviços ecossistêmicos de cada árvore foram estimados em GBP 16 (BRL 112) por ano (ROGERS et al., 2015), ao passo que, em Lisboa (Portugal), USD 159 (BRL 795) por árvore por ano (SOARES et al., 2011) e, no Brasil, R\$ 580,00 por árvore por ano (MENDES; OLIVEIRA, 2019). Considerando um período de 40 anos, McPherson et al. (2010) encontraram diferentes benefícios líquidos anuais, a depender do porte da árvore: entre USD 29 e 41 (BRL 145 a 205) para pequeno porte, USD 42 a 60 (BRL 210 a 300) para médio porte, USD 101 a 122 (BRL 505 a 610) para grande porte, e USD 142 a 146 (BRL 710 a 730) para coníferas, o que gera um valor médio de USD 85 (BRL 425) por árvore por ano. Neste artigo, essas sete referências científicas foram utilizadas para estimar o valor econômico por $\mathrm{m}^{2}$ de copa. No entanto, apesar do i-Tree ser utilizado frequentemente em pesquisas em diversos locais do mundo (MCPHERSON et al., 2010; SOARES et al. , 2011; HILDE; PATERSON, 2014; ROGERS et al., 2015; 
MCPHERSON; VAN DOORN; GOEDE, 2016; WANG et al., 2018), ele foi calibrado inicialmente para árvores de clima temperado, como EUA e Europa, necessitando, assim, de novos inputs para árvores tropicais, representando, dessa forma, uma lacuna a ser explorada.

Considerando que a protagonista desta narrativa dos serviços ecossistêmicos é a própria sociedade, a qual não dispõe de recursos avançados para uma simulação computacional na ótima ferramenta que é o i-Tree, o objetivo desta pesquisa foi desenvolver um modelo simplificado de valoração monetária baseado na magnitude da copa, a fim de possibilitar as pessoas leigas a estimarem o valor das árvores que as cercam, percebendo a importância da arborização urbana na criação de cidades mais resilientes, e, ademais, auxiliar os gestores ambientais na elaboração de políticas públicas, para que os critérios de remoção, plantio e incentivo não sejam subjetivos. Por fim, aplicou-se o método em um estudo de caso numa cidade de clima tropical.

\section{MATERIAL E MÉTODOS}

A pesquisa foi realizada em Piracicaba/SP/Brasil, cidade a qual se encontra a Escola Superior de Agricultura "Luiz de Queiroz", Universidade de São Paulo (ESALQ/USP). Situa-se nas coordenadas geográficas $22^{\circ}$ $42^{\prime} \mathrm{S}$ e $47^{\circ} 38^{\prime}$ W, na transição dos biomas Mata Atlântica e Cerrado (nas cotas mais elevadas), composta predominantemente pela floresta estacional semidecidual no domínio da Depressão Periférica Paulista, com árvores perenifólias e decíduas (RODRIGUES, 1999), cujo clima, segundo a classificação de Köppen-Geiger, é Cfa com transição para o Cwa, definido como subtropical, com invernos frios e secos, e verões quentes e chuvosos, temperatura média anual de $22^{\circ} \mathrm{C}, 546 \mathrm{~m}$ de altitude em relação ao nível do mar e precipitação média de $1300 \mathrm{~mm}$ por ano (ENGENHARIA DE BIOSSISTEMAS, 2021).

Mendes (2021) propôs um método que estima a quantidade de árvores urbanas baseado na população do município. Em outras palavras, uma árvore a cada seis habitantes, em média. Piracicaba, com população estimada em 364.571 habitantes (Censo 2010), possui 60.146 árvores no sistema viário (ROLLO, 2014), sendo que as sete mais abundantes correspondem a aproximadamente metade da arborização urbana. São elas, em ordem decrescente: Murraya paniculata (L.) Jack (falsa-murta), Licania tomentosa (Benth.) Fritsch (oiti), Cenostigma pluviosum (DC.) L.P.Queiroz (sibipiruna), Lagerstroemia indica L. (resedá), Schinus molle L. (falso-chorão ou aroeira-salsa), Magnolia champaca (L.) Baill. ex Pierre (magnólia) e Handroanthus chrysotrichus (Mart. ex DC.) Mattos (ipê-amarelo).

Encomendado pela Prefeitura Municipal de Piracicaba (2020) a um valor estimado de R\$196.286,67 (Edital: 0085/2019, Nº Processo: 
$57.817 / 2019$, com valor fechado em $\mathrm{R} \$ 66.500,00$ ), foi realizado um estudo atualizado, o qual estimou 96.448 árvores no sistema viário (530.094 no perímetro urbano); todavia, como não foram identificadas as espécies, esta pesquisa adotará os dados do inventário amostral de Rollo (2014), a qual amostrou 9,6\% dos quarteirões existentes no município.

O método de valoração aqui proposto baseou-se majoritariamente na magnitude da copa, uma vez que a maior parte dos serviços ecossistêmicos na área urbana são provenientes dela (SILVA; PIMENTEL, 2019). Fez-se uma interação de três variáveis: (i) área da copa, em m2; (ii) índice de área foliar (IAF, ou Leaf Area Index - LAI, em inglês), número adimensional e (iii) parâmetro $\mathrm{R} \$ / \mathrm{m}^{2}$ de copa. Para a obtenção de cada variável, tem-se:

(i) Estimada utilizando uma trena ou a calibração dos passos, calculado pela fórmula matemática: $A=\pi \cdot r^{2}$, onde $A=$ área, $\pi=3,1416$ e $r$ = raio; se a copa da árvore for ovalada, basta aplicar a fórmula da elipse: $A=\pi \cdot R \cdot r$, onde $R=$ raio maior e $r=$ raio menor;

(ii) Correspondente à razão entre a área foliar do dossel e sua respectiva projeção sobre o solo (WATSON, 1947). Conceitualmente, difere-se entre LAl efetivo e LAI verdadeiro, sendo que o efetivo pode ser aproximadamente $50 \%$ menor que o verdadeiro. Isso ocorre devido à aglutinação das folhas, ou seja, a distribuição espacial das folhas na copa acontece de modo aleatório. Cada um tem a sua aplicação: enquanto o LAI verdadeiro representa melhor as atividades fotossintéticas, como taxa de fotossíntese e evapotranspiração, o LAl efetivo é mais voltado às análises de interceptação da radiação e regime radiativo dentro e abaixo da copa (SHINZATO et al., 2015). Neste modelo, portanto, adotou-se o valor do LAI verdadeiro, multiplicando o valor estimado do LAl efetivo por 1,5. Foi considerado o conceito do Gap Fraction (arranjo geométrico das aberturas das folhas na copa - ou porcentagem de céu aberto) como método não destrutivo indireto para estimativa do LAl efetivo, evitando-se imagens com muitos troncos e galhos para não sobrestimar os valores (NORMAN; CAMPBELL, 1989), por meio de fotografias hemisféricas tiradas com lentes do tipo olho de peixe (fisheye) acopladas a um smartphone (no caso, Motorola $2^{a}$ Geração - Android 6.0) e posterior processamento com o programa gratuito Gap Light Analyzer (GLA) versão 2.0 (FRAZER et al., 1999). O processamento GLA (Figura 1) consiste em, basicamente, cinco etapas, respectivamente: primeiro, carregar a imagem .bmp ou .jpg; segundo, registrar a imagem com a área circular de interesse; terceiro, ajustar as configurações (ou adotar padrão); quarto, classificação da imagem por meio da função Threshold..., convertendo os pixels em um arquivo binário (preto e branco), onde o preto indica copa e o branco indica céu aberto; quinto, calcular os resultados da estrutura do dossel, tais como abertura de copa (em porcentagem) e LAl efetivo. Destaca- 
-se que as lentes fisheye podem ser obtidas a um preço relativamente acessível, ao valor de $\mathrm{R} \$ 25,00$. Tomou-se como base o inventário de Rollo (2014) para valoração do patrimônio arbóreo de Piracicaba;

(iii) O parâmetro $\mathrm{R} \$ / \mathrm{m}^{2}$ de copa foi estimado a partir de uma revisão bibliográfica com trabalhos sobre a temática. Este ponto pode representar uma limitação desta pesquisa, uma vez que o comportamento fisiológico das árvores mudam conforme cada localidade, sobretudo em clima tropical. Além disso, o uso de diferentes moedas fiduciárias com câmbio flutuante ao longo do tempo dificultam a padronização deste parâmetro.

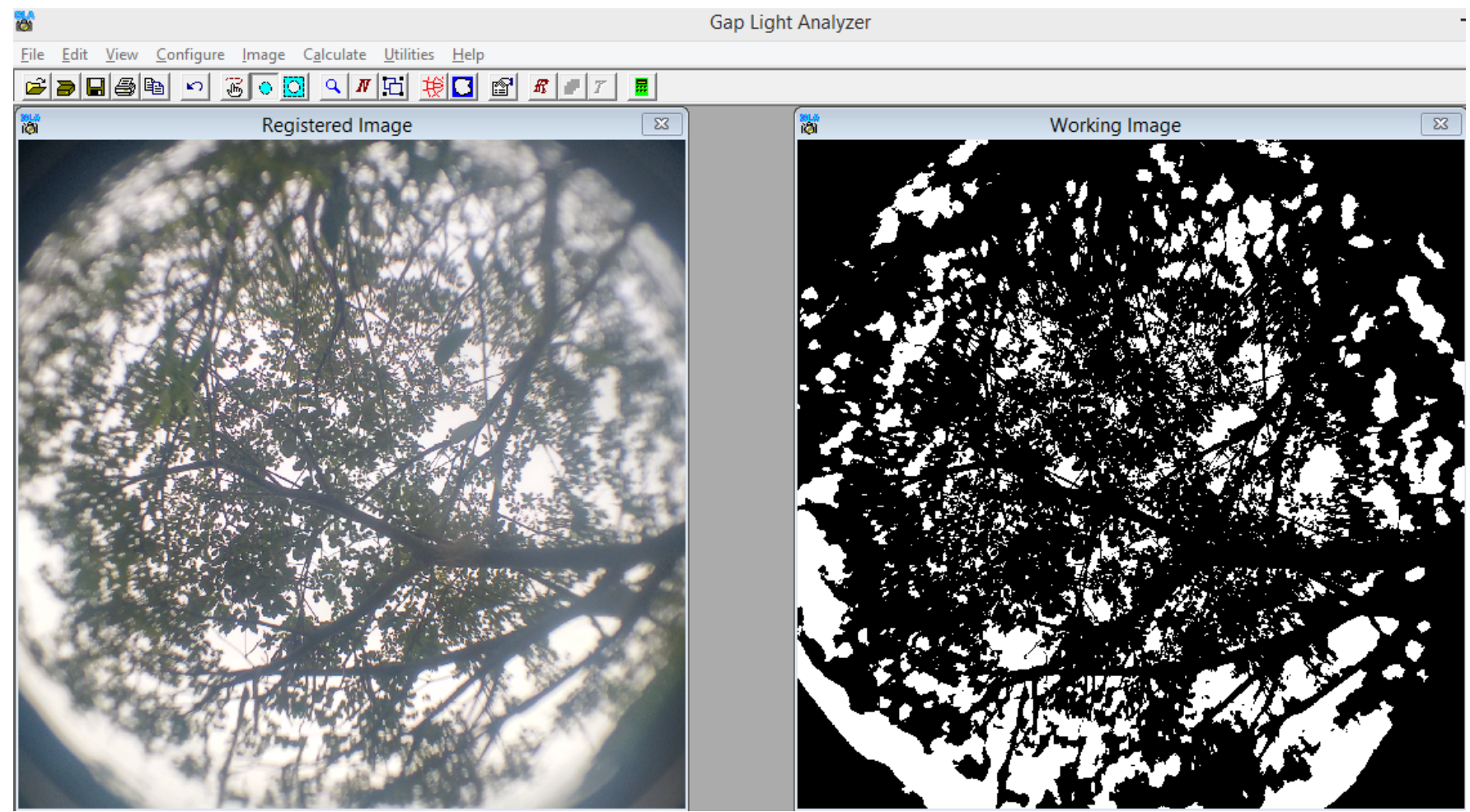

FIGURA 1. Processamento GLA

para análise da estrutura da copa (no exemplo, ipê amarelo), adotando no Threshold... o valor do pixel igual a 192 como limiar de separação do preto/branco, valor este que representou adequadamente a foto hemisférica. Fonte: Autores.

Assim, a fórmula de valoração proposta foi (Equação 1):

$V=C \cdot L \cdot P$

onde $\mathrm{V}=$ valor monetário, $\mathrm{C}=$ área da copa, $\mathrm{L}=$ Leaf Area Index e $\mathrm{P}$ = parâmetro

As medições de campo foram feitas em fevereiro de 2020, das 18 h00 às 19h00, hora em que a radiação difusa é mais intensa, ou seja, uma lacuna um pouco menor que uma hora antes do pôr do sol, com preferência por dias nublados, evitando que a radiação direta interferisse nas estimativas. Foram avaliadas as sete espécies de maior representatividade na cidade, com cinco repetições para cada espécie, sendo todas em calçadas, coletando os diâmetros de copa, área foliar (das folhas, folíolos ou foliólulos) e as fotos hemisféricas. 
Para fins estatísticos de cada espécie adotou-se a variável mediana ao invés da média, para evitar que algum exemplar outlier enviesasse as estimativas. Houve duas dificuldades para a execução deste campo: (i) o trânsito neste horário, que exige constante atenção para evitar acidentes e (ii) interferências dos exemplares com mobiliários urbanos e outras árvores vizinhas, o que poderia enviesar os resultados, sendo necessário encontrar outros indivíduos para a amostragem. O período correspondeu ao verão no hemisfério sul, época em que as árvores estavam com elevado vigor fotossintético em virtude da abundância de chuvas.

A Figura 2 mostra estimativas dos LAls em todo o mundo, sendo os maiores valores próximos a 7, correspondente às florestas tropicais. 0 Brasil, de um modo geral, fica com média de 3,72, embora seu território, se detalhado a nível de estado, varie entre 0,56 na caatinga em Sergipe (mais baixo) até 4,97 na Amazônia em Amazonas (mais alto).

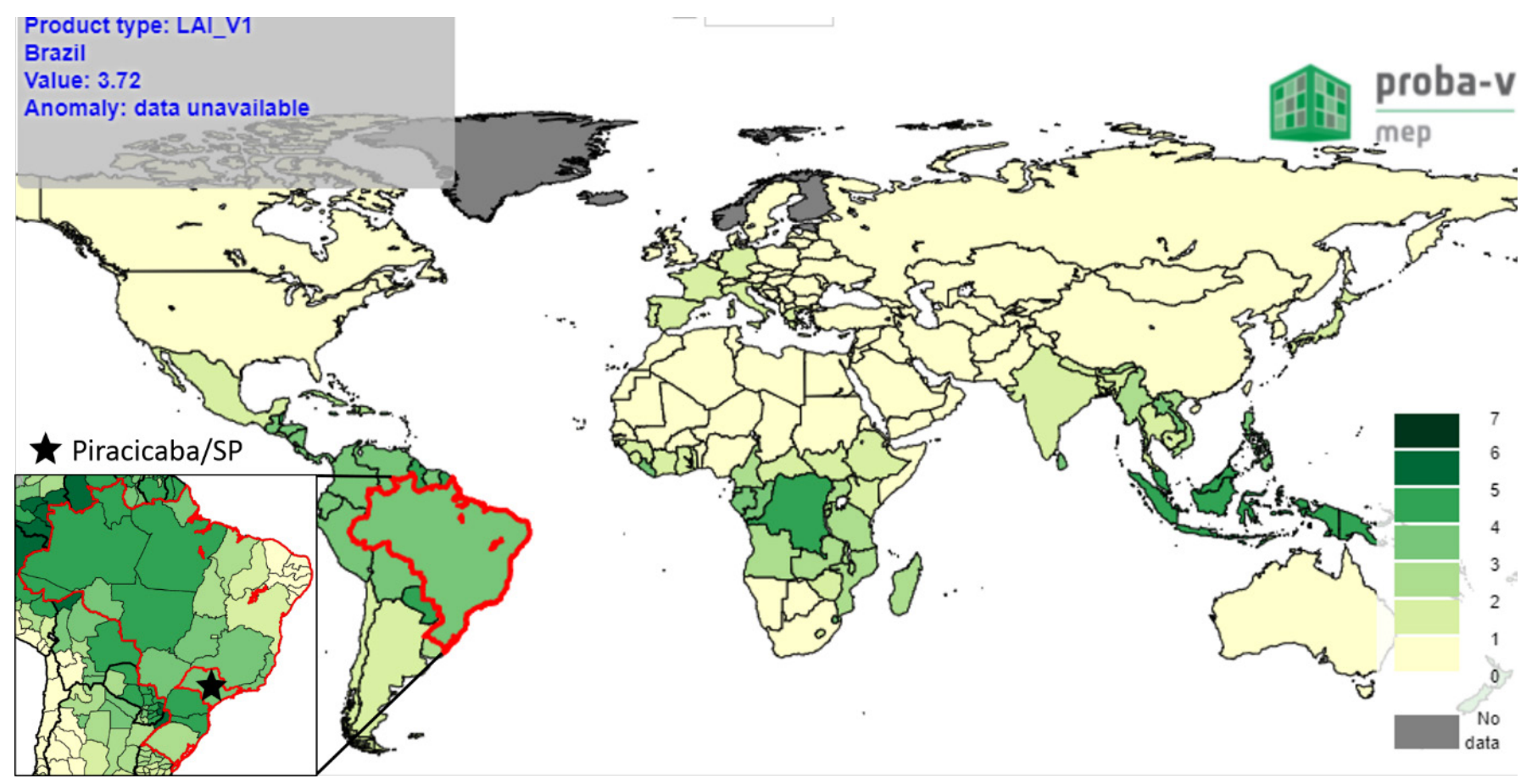

FIGURA 2. Estimativas do LAI para os países do mundo, com destaque para Piracicaba/SP

$(3,61)$. Fonte: Copernius Global Land Service, hospedado por VITO (2021).

Todos os nomes científicos foram extraídos do site oficial Flora do Brasil 2020, e o câmbio baseado no Banco Central do Brasil (2021), considerando a cotação em junho de 2021, ou seja, USD 1 equivalente a BRL 5, EUR 1 equivalente a BRL 6, e GBP 1 equivalente a BRL 7. 


\section{RESULTADO E DISCUSSÃO}

A Figura 3 mostra a comparação das sete espécies estudadas com suas respectivas estruturas de copa, sendo estas captadas com a lente tipo olho de peixe.
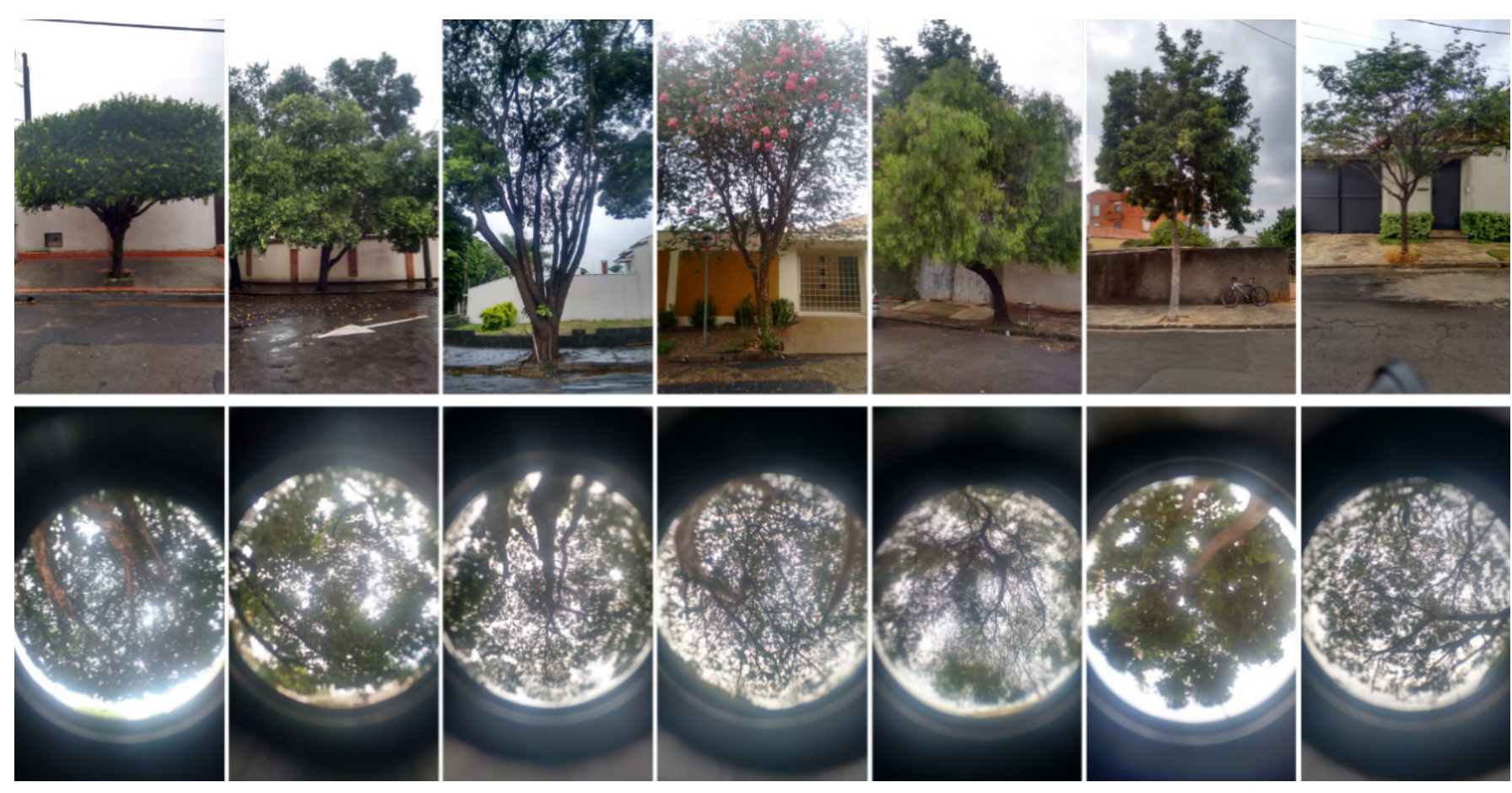

FIGURA 3 Respectivamente, falsamurta, oiti, sibipiruna, resedá, falso-chorão, magnólia e ipêamarelo. Fonte: Autores.
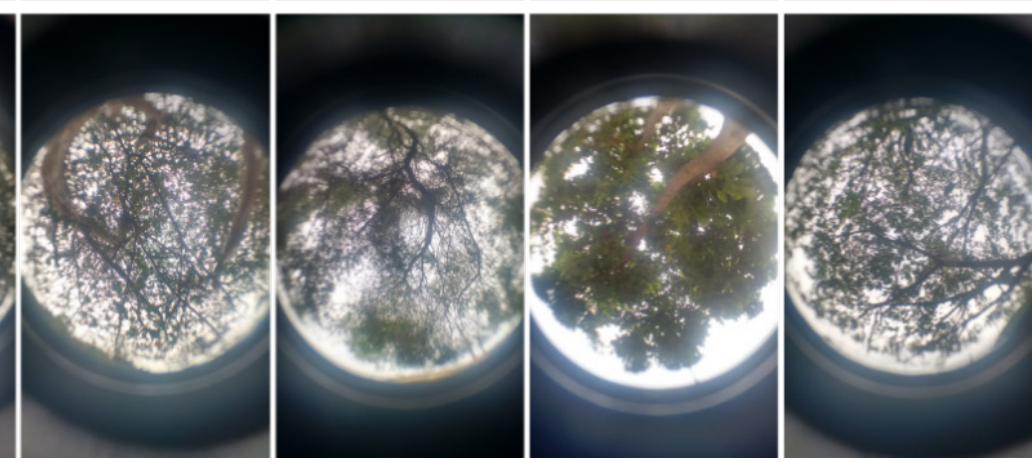

O conhecimento do tamanho e a estrutura da copa é necessário na proposição desta metodologia de valoração monetária da árvore. Dessa forma, encontraram-se altos valores de Correlação de Pearson: (i) positiva entre o LAI verdadeiro e a Área foliar $\left(R^{2}=0,7814\right)$, ou seja, quanto maior o tamanho da folha, maior o valor do LAl e, consequentemente, maiores serão os serviços ecossistêmicos; (ii) negativa entre - LAl e a Abertura da copa, isto é, quanto mais aberta a copa (maior visualização do céu aberto sob a copa), menor o valor do LAI $\left(R^{2}=\right.$ 0,9284) (Figura 4), alinhado com o que foi encontrado por Silva e Pimentel (2019). 


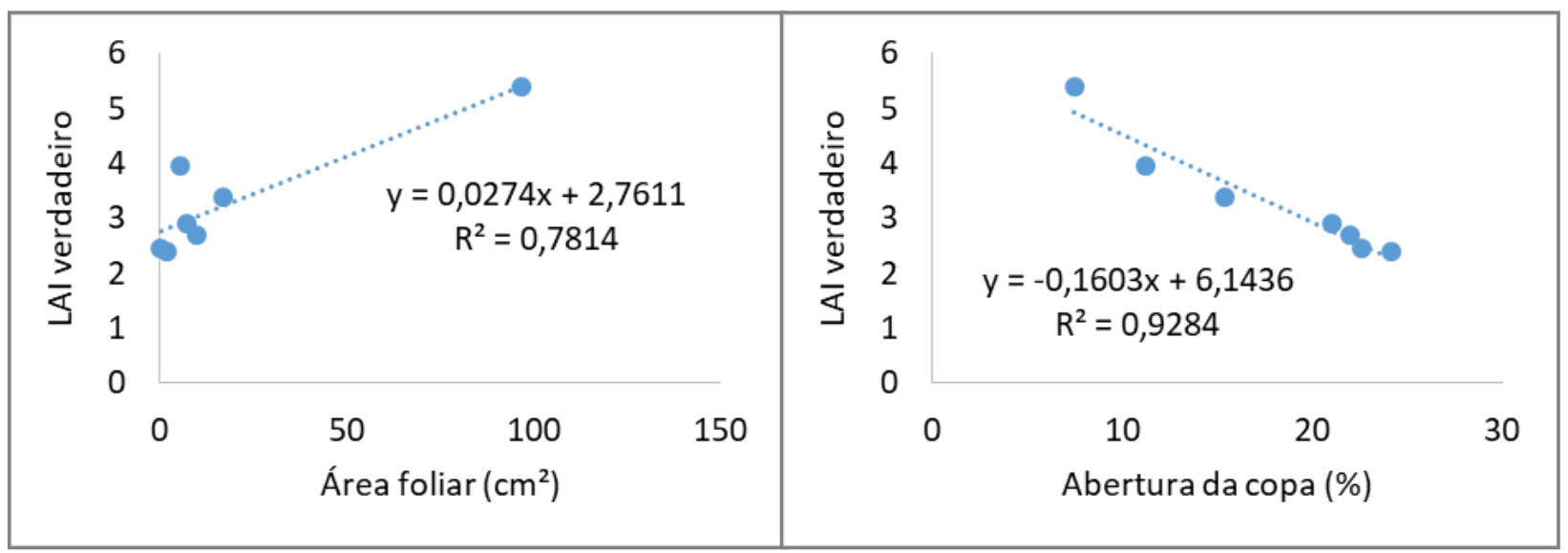

FIGURA 4. Correlação de Pearson entre o LAI verdadeiro e a Área

foliar, e o LAl verdadeiro e a Abertura de copa. Fonte: os autores

TABELA 01. Pesquisas sobre valoração monetária de árvores e sua conversão para encontrar o parâmetro "P" (R $\$ / \mathrm{m}^{2}$ de copa).

A revisão bibliográfica com sete pesquisas recentes desde 2010 sobre o tema, em diferentes locais do mundo, apontou média e mediana com valores próximos, ou seja, saldo líquido anual de $R \$ 6,1 / \mathrm{m}^{2}$ de copa (mediana) e R $\$ 6,0 / \mathrm{m}^{2}$ de copa (média), o equivalente a USD 1.2 (considerando a cotação de junho de 2021), considerando uma árvore típica com $5 \mathrm{~m}$ de raio (logo, $10 \mathrm{~m}$ de diâmetro e $75 \mathrm{~m}^{2}$ de área projetada) (Tabela 1).

Fonte: Autores.

\begin{tabular}{|c|c|c|c|c|c|}
\hline Fonte & Ano & Título & $\begin{array}{l}\text { Saldo líqui- } \\
\text { do/ árv/ano }\end{array}$ & $\begin{array}{l}\text { Conversão } \\
\text { BRL }\end{array}$ & $\begin{array}{c}\text { "P" } R \$ / \\
m^{2}\end{array}$ \\
\hline $\begin{array}{l}\text { McPherson } \\
\text { et al. }\end{array}$ & 2010 & $\begin{array}{c}\text { Northern California coast community } \\
\text { tree guide: benefits, costs, and strategic } \\
\text { planting }\end{array}$ & USD 85 & BRL 425 & 5,7 \\
\hline $\begin{array}{l}\text { Soares et } \\
\text { al. }\end{array}$ & 2011 & $\begin{array}{c}\text { Benefits and costs of street trees in Lis- } \\
\text { bon, Portugal }\end{array}$ & USD 159 & BRL 795 & 10,6 \\
\hline $\begin{array}{l}\text { Hilde e Pa- } \\
\text { terson }\end{array}$ & 2014 & $\begin{array}{l}\text { Integrating ecosystem services analysis } \\
\text { into scenario planning practice: wAccou- } \\
\text { nting for street tree benefits with i-Tree } \\
\text { valuation in Central Texas }\end{array}$ & USD 100 & BRL 500 & 6,7 \\
\hline Rogers et al. & 2015 & $\begin{array}{c}\text { Valuing London's Urban Forest: Results } \\
\text { of the London i-Tree Eco Project }\end{array}$ & GBP 16 & BRL 112 & 1,5 \\
\hline $\begin{array}{l}\text { McPherson, } \\
\text { van Doorn e } \\
\text { Goede }\end{array}$ & 2016 & $\begin{array}{c}\text { Structure, function and value of street } \\
\text { trees in California, USA }\end{array}$ & USD 92 & BRL 460 & 6,1 \\
\hline Wang et al. & 2018 & $\begin{array}{l}\text { Street trees in a Chinese forest city: } \\
\text { Structure, benefits and costs }\end{array}$ & USD 59 & BRL 295 & 3,9 \\
\hline $\begin{array}{l}\text { Mendes e } \\
\text { Oliveira }\end{array}$ & 2019 & $\begin{array}{l}\text { Percepção da arborização urbana por } \\
\text { estudantes de marketing }\end{array}$ & BRL 580 & BRL 580 & 7,4 \\
\hline
\end{tabular}


TABELA 02. Valoração monetária do patrimônio arbóreo de Piracicaba/SP, sendo $\varnothing$ copa = diâmetro de copa, $\mathrm{C}$ = área da copa, $\mathrm{AF}=$ área foliar, LAl efet. $=\mathrm{LAl}$ efetivo, e LAl verd. $=\mathrm{LAl}$ verdadeiro, com as respectivas valoração individual e valoração total. Fonte: Autores.
Dessa forma, uma vez obtido o parâmetro "P", o estudo de caso referente à arborização urbana de Piracicaba apontou a sibipiruna madura como uma das espécies mais importantes na cidade. Isso se deve ao relevante tamanho da copa, que pode ultrapassar $10 \mathrm{~m}$ de diâmetro. Originária da Mata Atlântica, semidecídua, com floração na primavera, entre fim de agosto e meados de novembro, pode chegar a $16 \mathrm{~m}$ de altura, sendo uma das principais espécies utilizadas na arborização urbana do centro-sul do Brasil (LORENZI, 1992).

Em tupi, "sibipiruna" significa "casca preta", justificando seu tronco escamoso. De modo geral, está nas ruas piracicabanas há pelo menos 50 ou 60 anos, cujo plantio foi realizado predominantemente nas décadas de 1950 e 1960, devido à Lei do habite-se de 1942, uma lei municipal que exigia que cada morador plantasse uma árvore em sua calçada para direito ao certificado de residência. Como Piracicaba não tinha viveiro municipal nesta época, as mudas vieram da cidade vizinha, Rio Claro/SP, que dispunha de grandes quantidades dessa espécie.

O oiti, por sua vez, foi outra espécie de destaque, com mais de R\$ 1.000,00 por ano de benefícios, com características de ocorrência e altura semelhantes à sibipiruna, porém, perenifólia, sendo uma das espécies mais abundantes no oeste do estado de São Paulo (MENDES, 2021). A mediana da valoração monetária de cada árvore foi de um benefício estimado em $\mathrm{R} \$ 415,00$ / ano, valor este muito próximo do praticado no mercado de comércio de árvores, que é de $R \$ 4.000,00$ por árvore com cerca de 10 anos de idade (FÁBRICA DE ÁRVORES, 2021). A valoração de praticamente metade da arborização urbana de Piracicaba, correspondente à somatória das sete espécies analisadas, contabilizou R\$20.449.687,00. Baseado neste valor, pode-se inferir que a cidade tem um patrimônio arbóreo anual estimado em $\mathrm{R} \$$ 40.899.373,00, equivalente a USD 8.179.875,00 milhões (Tabela 2).

\begin{tabular}{|c|c|c|c|c|c|c|c|c|c|c|}
\hline Espécie & $\begin{array}{c}\varnothing \text { copa } \\
(\mathrm{m})\end{array}$ & $\underset{(m 2)}{C}$ & $\underset{(\mathrm{cm} 2)}{\mathrm{AF}}$ & $\begin{array}{l}\text { LAI } \\
\text { efet. }\end{array}$ & $\begin{array}{c}\text { LAI } \\
\text { verd. }\end{array}$ & $\begin{array}{l}\text { Abertura } \\
\text { copa (\%) }\end{array}$ & $\begin{array}{l}\text { Quanti- } \\
\text {-dade }\end{array}$ & $\begin{array}{l}\text { Parâmetro } \\
\text { P (R\$/m2) }\end{array}$ & $\begin{array}{l}\text { Valoração } \\
\text { individual }\end{array}$ & $\begin{array}{l}\text { Valora- } \\
\text { ção total }\end{array}$ \\
\hline $\begin{array}{l}\text { Falsa- } \\
\text { - murta }\end{array}$ & 4 & 13 & 5,5 & 2,63 & 3,9 & 11,2 & 9.780 & 6,1 & $\mathrm{R} \$ 304$ & $\begin{array}{c}\mathrm{R} \$ \\
2.973 .588\end{array}$ \\
\hline Oiti & 9 & 64 & 17,2 & 2,25 & 3,4 & 15,4 & 6.231 & 6,1 & $\mathrm{R} \$ 1.317$ & $\begin{array}{c}R \$ \\
8.205 .627\end{array}$ \\
\hline Sibipiruna & 11 & 95 & 0,3 & 1,64 & 2,5 & 22,6 & 3.873 & 6,1 & $\mathrm{R} \$ 1.434$ & $\begin{array}{c}\mathrm{R} \$ \\
5.553 .919\end{array}$ \\
\hline Resedá & 5 & 20 & 7,2 & 1,94 & 2,9 & 21 & 3.861 & 6,1 & $R \$ 350$ & $\begin{array}{c}R \$ \\
1.353 .198 \\
\end{array}$ \\
\hline $\begin{array}{l}\text { Falso- } \\
\text {-chorão }\end{array}$ & 6 & 28 & 2,2 & 1,59 & 2,4 & 24,2 & 1.883 & 6,1 & $\mathrm{R} \$ 414$ & $\begin{array}{c}R \$ \\
778.625\end{array}$ \\
\hline Magnólia & 4 & 13 & 97,0 & 3,59 & 5,4 & 7,5 & 1.834 & 6,1 & $\mathrm{R} \$ 415$ & $\begin{array}{c}\mathrm{R} \$ \\
761.375 \\
\end{array}$ \\
\hline $\begin{array}{l}\text { Ipê-ama- } \\
\text { relo }\end{array}$ & 6 & 28 & 9,9 & 1,79 & 2,7 & 22 & 1.768 & 6,1 & $R \$ 466$ & $\begin{array}{c}R \$ \\
823.355\end{array}$ \\
\hline
\end{tabular}


Neste estudo de caso, em específico, uma árvore urbana chama a atenção: a sapucaia (Lecythis pisonis Cambess.). Também conhecida como Sapucaia da Moraes (em virtude da Rua Moraes Barros, local em que se encontra) ou Sapucaia do XV (devido à localização próxima ao Estádio Municipal do Esporte Clube XV de Novembro de Piracicaba), foi plantada em 1918 pela família Caprânico para celebrar o fim da Primeira Guerra Mundial, tornando-se uma árvore símbolo da cidade, tombada pelo Patrimônio Histórico e Cultural. Possui $12 \mathrm{~m}$ de altura, 4,80 m de CAP (Circunferência à Altura do Peito), $450 \mathrm{~m}^{2}$ de copa, e $\mathrm{LAI}$ verdadeiro estimado em 3,0. Aplicando-se a metodologia proposta, tem-se: $V=$ C.L.P $\rightarrow V=450 \times 3,0 \times 6,1 \rightarrow R \$ 8.158,00$ em serviços ecossistêmicos ao ano. Além disso, tem toda a questão do valor histórico, o qual pode ser difícil de estimar por causa da subjetividade, o que poderia agregar um valor ainda maior (Figura 5).
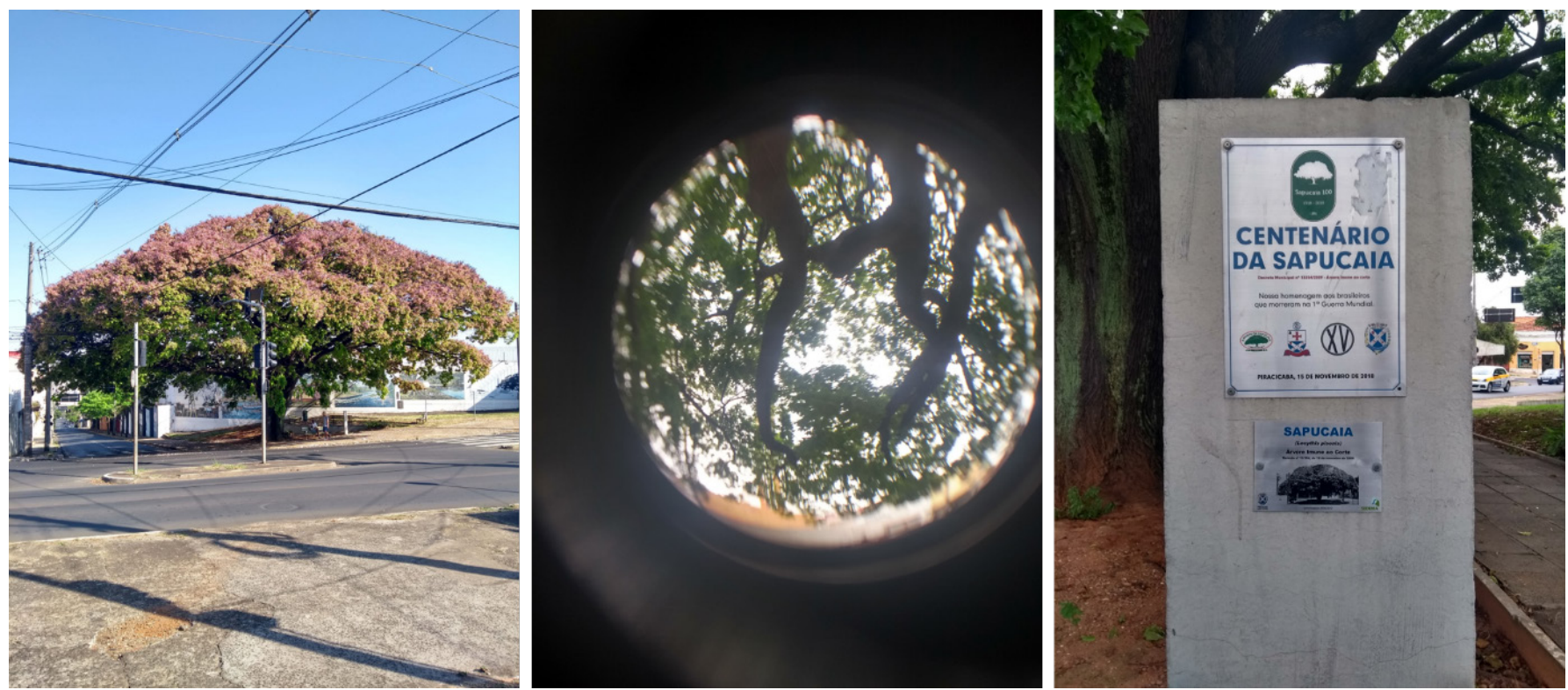

FIGURA 5. Exemplar centenário da majestosa sapucaia em área urbana. Fonte: Autores.

A discussão de um outro ponto é essencial: a existência de espécies invasoras, seja no ambiente rural ou urbano, como a leucena (Leucaena leucocephala (Lam.) de Wit), originária na América Tropical, de rápido crescimento, a qual foi trazida ao Brasil para servir de alimento na pecuária. Embora possa trazer algum serviço ecossistêmico imediato, seu valor (assim como qualquer outra espécie invasora) deve ser zero, visto que a potencialidade de danos futuros supera os benefícios. Ocupando praticamente toda a margem dos rios, ela possui um efeito chamado alelopatia, responsável por liberar compostos químicos no solo, evitando que outra planta se desenvolva e, portanto, deve ser erradicada (PREFEITURA MUNICIPAL DE PIRACICABA, 2020).

Não necessariamente o simples fato de uma espécie ser exótica deve 
FIGURA 6. Danos causados pela leucena no contrapiso (A e B) e no reboco (C), espécie considerada invasora, que tem comportamento agressivo. Fonte: Arquivo pessoal de Silvia Bonato (A e B) e Flávio Mendes (C) (2021)

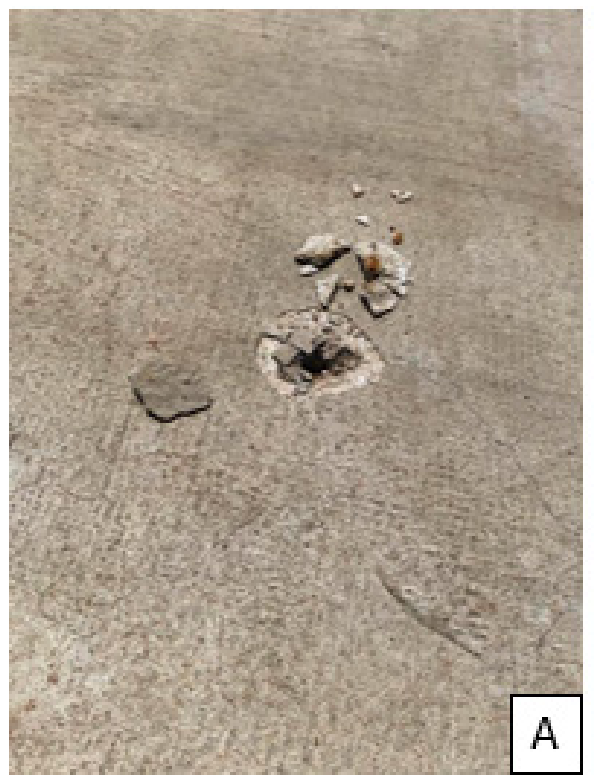

zerar a sua valoração, conforme foi mostrado nos estudos apresentados na Tabela 1, onde todos consideraram ambas (nativa e exótica) para a valoração. Em Santiago do Chile, por exemplo, cidade de clima tipo mediterrâneo (Csb), 86\% da arborização urbana é exótica (HERNÁNDEZ; VILLASEÑOR, 2018).

No caso da leucena, suas sementes são danosas à construção civil, uma vez que caem nos rios, misturam-se com a areia e, consequentemente, prejudicam a qualidade de contrapisos e rebocos, podendo emergir das camadas superficiais (de até $1 \mathrm{~cm}$ ) quando aquecida pela junção do impermeabilizante com a água da chuva, ocasionando trincas (Figura 6).

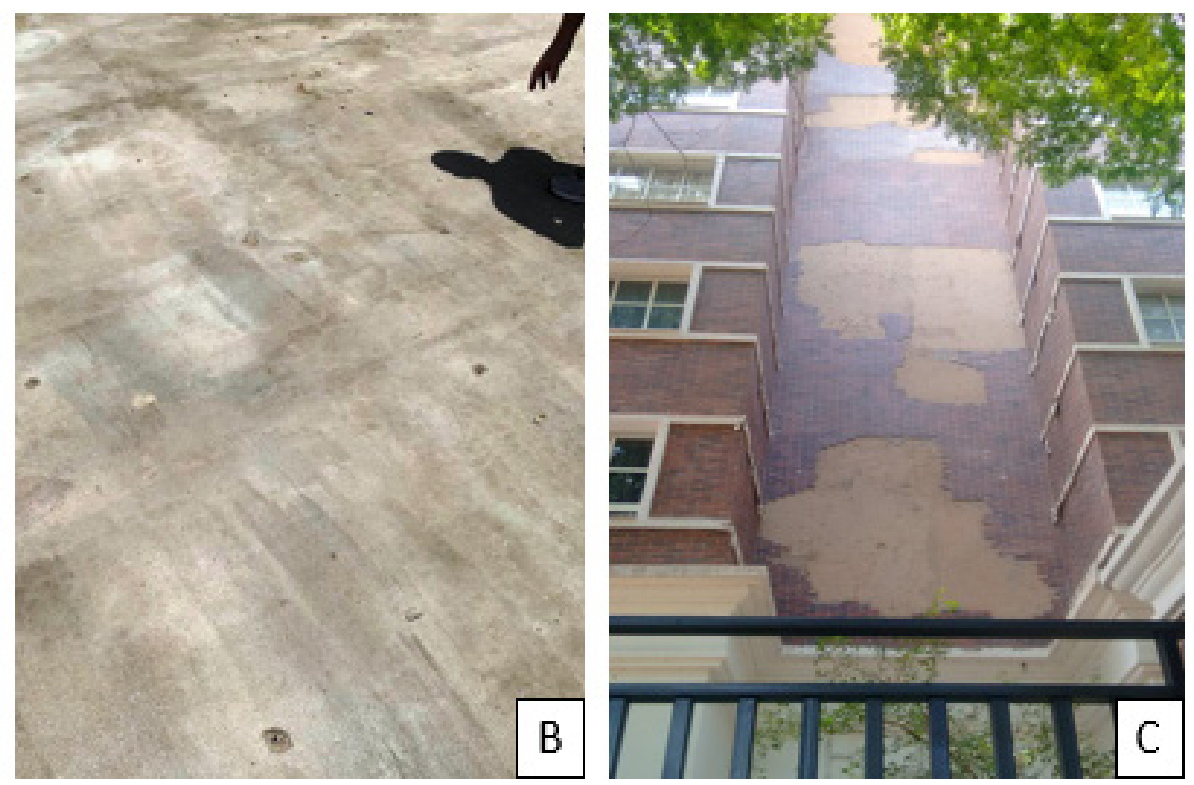

Desde 1970 a Pegada Ecológica da Terra ultrapassou a marca da sustentabilidade, precisando, atualmente, de 1,56 planeta Terra para suprir as necessidades humanas; se continuar neste ritmo, em meados de 2030 é possível que o sistema natural entre em colapso, quando a demanda pelos recursos será o dobro do que a Terra poderá oferecer (WWF, 2020).

Neste contexto, a arborização urbana aparece como um dos fatores capazes de mitigar esse efeito. Contudo, as dificuldades para o plantio de novas árvores nas cidades são diversas, desde financeiras até a rejeição do morador, sob a justificativa de sujeiras das folhas, entupimento de calhas, conflitos com fiação elétrica e queda de árvores e galhos (MENDES; OLIVEIRA, 2019), os quais podem ser minimiza- 
dos quando realizado um acompanhamento frequente das condições fitossanitárias, sobretudo das que apresentam elevado risco de queda, apesar das árvores com riscos intermediário e baixo serem difíceis de prever a queda (KOESER et al., 2020). Essa conjuntura resume bem o acrônimo norte-americano NIMBY ("not-in-my-backyard"), na qual as pessoas desejam ambientes sustentáveis, floresta urbana, serviços ecossistêmicos, infraestrutura verde etc., contanto que não comprometam os objetivos pessoais, ou seja, a aceitação das árvores parece ser quase que unânime, desde que não seja em frente à minha casa.

Uma alternativa para suprir esta lacuna pode ser incentivando a sociedade quanto à importância de novos plantios e da preservação do patrimônio existente, baseado no modelo de valoração monetária aqui proposto; havendo sinergia entre poder público e sociedade seria possível construir ambientes mais verdes por meio da criação do IPTU Verde (Imposto Predial e Territorial Urbano), na qual o morador teria um desconto neste imposto anual por conservar uma árvore em sua calçada ou área impermeável no quintal, como já ocorre em Araraquara/SP, São Carlos/SP, Curitiba/PR e Vila Velha/ES, mas divergem entre si quanto aos critérios adotados (CUNHA; MARTINEZ; NOSSA, 2013). No caso de Piracicaba/SP, tomando como base o valor médio de $\mathrm{R} \$ 415,00 /$ ano/árvore, um desconto de $5 \%$ equivaleria a $\mathrm{R} \$ 20,75$. Se considerar que a cidade tem 60.146 árvores para os 207.359 imóveis registrados, seria um investimento de $R \$ 1.248 .030,00$ para a Prefeitura, perante os R\$41 mi de benefícios líquidos anuais estimados. Ademais, a Lei Orçamentária Anual (LOA) do município é de R\$128 mi, logo, o desconto de $5 \%$ corresponderia a $0,98 \%$ do total previsto na arrecadação.

Por fim, de modo a engajar a sociedade na temática, são apresentadas duas possibilidades:

- A primeira, levando em consideração o uso cada vez mais frequente da tecnologia, com a criação de um aplicativo na qual os próprios moradores voluntários, previamente capacitados por meio de treinamentos em cursos e palestras, cadastrariam as árvores próximas de sua vivência, levando em consideração as características qualiquantitativas, tais como identificação da espécie, endereço, altura, diâmetro de copa, DAP, condição fitossanitária etc. Uma vez de posse dos resultados obtidos, o Poder Público municipal teria uma visão mais ampla de onde atuar na gestão da arborização urbana, sobretudo quanto ao risco de queda;

- A segunda seria estimar e disponibilizar o valor monetário de algumas árvores urbanas estratégicas (como a sapucaia centenária), em placas com QRCode, para disseminar a ideia, por exemplo, como foi realizado em Lisle (Illinois/EUA), indicando o retorno anual dos serviços ecossistêmicos (Figura 7). 
FIGURA 7. Placa com QRCode indicando o quanto uma determinada árvore pode retornar em serviços ecossistêmicos; em inglês, "Esta árvore devolve \$_ em benefícios para o nosso meio ambiente no próximo ano". Fonte: The Morton Arboretum (2021).

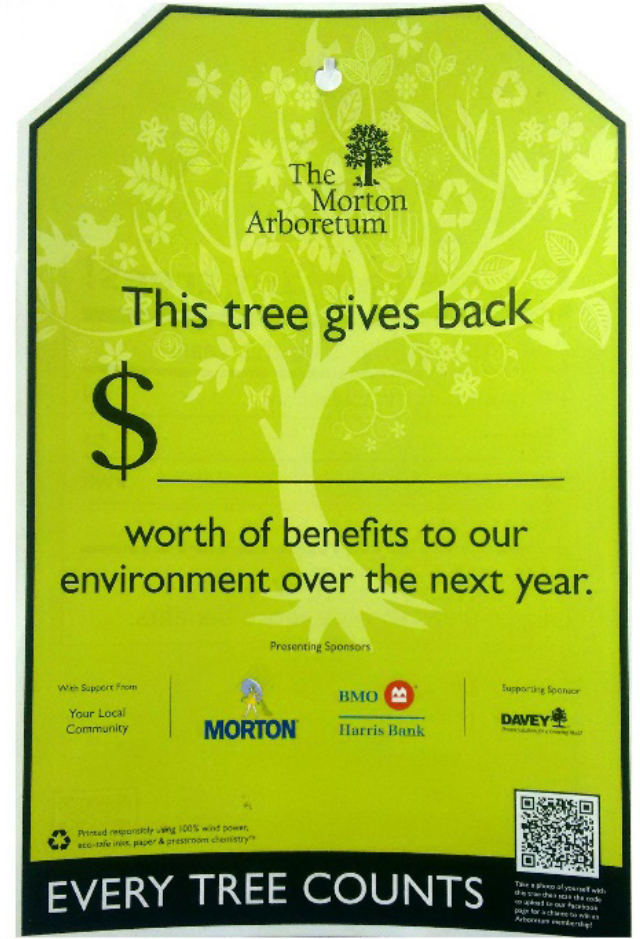

\section{CONCLUSÃO}

O método simplificado de valoração monetária da arborização urbana indicou que o valor das árvores em Piracicaba/SP/Brasil pode ser estimado em R \$ 40.899.373,00 ao ano, na qual o estreitamento das relações entre prefeitura e cidadãos poderá melhorar o ecossistema urbano e, assim, a qualidade de vida. Entender o contexto de um problema e as lacunas a serem preenchidas é fundamental para a proposição das soluções, na qual o método aqui proposto pode servir de parâmetro para políticas públicas municipais.

Não existe um método perfeito, o que há são aproximações da realidade, por isso, é importante reconhecer as limitações de cada modelo, ressaltando que os serviços ecossistêmicos prestados pela arborização urbana não são exclusivamente econômicos, mas também uma questão de igualdade social e de distribuição geoespacial. Estudos futuros poderão buscar a confecção de uma lista contendo dados primários sobre as estimativas do LAl efetivo e verdadeiro das espécies mais frequentes utilizadas na arborização urbana, a fim de servir de base para novas valorações.

\section{AGRADECIMENTOS}

O presente trabalho foi realizado com apoio da Coordenação de Aperfeiçoamento de Pessoal de Nível Superior - Brasil (CAPES) - Código de Financiamento 001. 


\section{REFERÊNCIAS}

AFFOLDERBACH, J.; SCHULZ, C. Positioning Vancouver through urban sustainability strategies? The Greenest City 2020 Action Plan. Journal of Cleaner Production, v. 164, p. 676-685, 2017.

BANCO CENTRAL DO BRASIL. Cotação. 2021. Disponível em: <https://www.bcb.gov. br/>. Acesso em: 02 jul. 2021.

CITY OF VANCOUVER. Greenest City 2020 Action Plan. 2012. Disponível em: <https:// vancouver.ca/files/cov/Greenest-city-action-plan.pdf>. Acesso em: 28 jun. 2021.

CUNHA, D.S.A.; MARTINEZ, A.L.; NOSSA, V. Incentivos fiscais verdes e tributação extrafiscal: estudo sobre o IPTU verde no município de Vila Velha (ES) comparativamente a outros municípios. Revista Razão Contábil \& Finanças, v. 4, n. 1, p. 79-98, 2013.

ENGENHARIA DE BIOSSISTEMAS. Série de Dados Climatológicos do Campus Luiz de Queiroz de Piracicaba, SP. 2021. Disponível em: <http://www.leb.esalq.usp.br/leb/ postocon.html>. Acesso em: 02 jul. 2021.

ESCOBEDO, F.J.; GIANNICO, V.; JIM, C.Y.; SANESI, G.; LAFORTEZZA, R. Urban forests, ecosystem services, green infrastructure and nature-based solutions: Nexus or evolving metaphors? Urban Forestry \& Urban Greening, v. 37, p. 3-12, 2019.

FÁBRICA DE ÁRVORES. 2021. Disponível em: <https://www.fabricadearvores.com. $\mathrm{br} />$. Acesso em: 23 maio 2021.

FLORA DO BRASIL 2020. Jardim Botânico do Rio de Janeiro. Disponível em: <http:// floradobrasil.jbrj.gov.br/>. Acesso em: 02 jul. 2021.

FRAZER, G.W.; CANHAM, C.D.; LERTZMAN, K.P. Gap Light Analyzer (GLA): Imaging software to extract canopy structure and gap light transmission indices from truecolour fisheye photographs, users manual and program documentation. Burnaby, Millbrook: Simon Fraser University, Institute of Ecosystem Studies. 1999. 36 p.

HERNÁNDEZ, H.J.; VILLASEÑOR, N.R. Twelve-year change in tree diversity and spatial segregation in the Mediterranean city of Santiago, Chile. Urban Forestry \& Urban Greening, v. 29, p. 10-18, 2018.

HILDE, T.; PATERSON, R. Integrating ecosystem services analysis into scenario planning practice: Accounting for street tree benefits with i-Tree valuation in Central Texas. Journal of Environmental Management, v. 146, p. 524-534, 2014

I-TREE. About. 2020. Disponível em: <https://www.itreetools.org/about>. Acesso em: 29 jun. 2021.

KOESER, A.K.; SMILEY, E.T.; HAUER, R.J.; KANE, B.; KLEIN, R.W.; LANDRY, S.M.; SHERWOOD, M. Can professionals gauge likelihood of failure? - Insights from tropical storm Matthew. Urban Forestry \& Urban Greening, v. 52, p. 126701, 2020.

LORENZI, H. Árvores brasileiras: manual de identificação e cultivo de plantas arbóreas nativas do Brasil. Nova Odessa: Plantarum, 1992. 382 p.

MACEDO, S.S. Espaços livres. Paisagem Ambiente Ensaios, n. 7, p.15-56, 1995.

MCPHERSON, E.G.; SIMPSON, J.R.; PEPER, P.J.; CROWELL, A.M.N.; XIAO, Q. Northern California coast community tree guide: benefits, costs, and strategic planting. General Technical Report PSW-GTR-228. Albany: U.S. Department of Agriculture, Forest Service, Pacific Southwest Research Station. 2010. 118 p. 
MCPHERSON, E.G.; VAN DOORN, N.; GOEDE, J. Structure, function and value of street trees in California, USA. Urban Forestry \& Urban Greening, v. 17, p. 104-115, 2016.

MENDES, F.H.; OLIVEIRA, R.L.Z. Percepção da arborização urbana por estudantes de marketing. South American Development Society Journal, v. 5, n. 14, p. 189-205, 2019.

MENDES, F.H.; ROMERO, H.; SILVA FILHO, D.F. Cambio Climático adverso provocado por la urbanización sin planificación ni evaluación ambiental en Santiago de Chile. Revista de Geografía Norte Grande, n. 77, p. 191-210, 2020.

MENDES, F.H. Estimativa da quantidade de árvores urbanas a partir de modelo estatístico e criação do Índice Mendes de Arborização Urbana. Revista da Sociedade Brasileira de Arborização Urbana, v. 16, n. 1, p. 81-93, 2021.

NORMAN, J.M.; CAMPBELL, G.S. Canopy structure. In: PEARCY, R.W.;

EHLERINGER, J.; MOONEY, H.A.; RUNDEL, P.W. (org.). Plant Physiological Ecology: Field methods and instrumentation. London: Chapman and Hall, 1989. p. 301-325.

NOWAK, D.J.; CRANE, D.E.; STEVENS, J.C.; HOEHN, R.E.; WALTON, J.T.; BOND, J. A ground-based method of assessing urban forest structure and ecosystem services. Aboriculture \& Urban Forestry, v. 34, n. 6, p. 347-358, 2008.

OLIVEIRA, D.A.M.; GANDARA, F.B. Diagnóstico dos quintais permeáveis urbanos em função da autonomia de renda em seis bairros no município de Piracicaba. Revista Brasileira de Meio Ambiente e Sustentabilidade, v. 1, n. 1, p. 200-218, 2021.

PREFEITURA MUNICIPAL DE PIRACICABA. Plano Municipal de Arborização Urbana. Piracicaba: Secretaria de Defesa do Meio Ambiente, 2020. 307 p.

RODRIGUES, R.R. A vegetação de Piracicaba e municípios do entorno. Circular Técnica IPEF, n. 189, p. 1-17, 1999.

ROGERS, K.; SACRE, K.; GOODENOUGH, J.; DOICK, K. Valuing London's Urban Forest: Results of the London i-Tree Eco Project. Watford: Hill \& Garwood Printing Limited, 2015. 84 p.

ROLLO, L.C.P. Metodologias de quantificação de áreas verdes urbanas: mapeamento da cobertura arbórea e inventário florestal de árvores de rua em cidades do Estado de São Paulo. 2014. 103p. Tese (Doutorado em Ciências) - Escola Superior de Agricultura "Luiz de Queiroz", Universidade de São Paulo, Piracicaba, 2014.

ROMERO, H.; MENDES, F.H. Comodificação dos climas urbanos e criação de injustiças socioclimáticas em Santiago do Chile. ENTRE-LUGAR, v. 11, n. 22, p. 40$56,2020$.

ROMERO, H.; MENDES, F.H. La gentrificación de los climas urbanos y su influencia sobre las temperaturas de la superficie terrestre y el Covid-19 durante el año 2020 en Santiago de Chile. Geographicalia, n. 73, p. 155-176, 2021.

SHINZATO, P.; YOSHIDA, D.F.O.; DUARTE, D. O impacto da vegetação nos microclimas urbanos: Estimativa do Índice de Área Foliar - IAF pelo método de fotos hemisféricas. In: ENCONTRO NACIONAL, 13.; ENCONTRO LATINO-AMERICANO DE CONFORTO NO AMBIENTE CONSTRUÍDO, 9, 2015, Sumaré. Anais... Sumaré: ENCAC, ELACAC, 2015. p. 1-8.

SILVA FILHO, D.F.; TOSETTI, L.L. Valoração das árvores no Parque do IbirapueraSP: Importância da infraestrutura verde urbana. LABVERDE, n. 1, p. 11-25, 2010. 
SILVA, L.H.G.; PIMENTEL, R.M.M. Estrutura morfológica foliar da arborização urbana na manutenção do conforto térmico. Journal of Environmental Analysis and Progress, v. 4, n. 1, p. 104-109, 2019.

SOARES, A.L.; REGO, F.C.; MCPHERSON, E.G.; SIMPSON, J.R.; PEPER, P.J.; XIAO, $Q$. Benefits and costs of street trees in Lisbon, Portugal. Urban Forestry \& Urban Greening, v. 10, n. 2, p. 69-78, 2011.

SOCIEDADE BRASILEIRA DE ARBORIZAÇÃO URBANA (SBAU). Carta a Londrina e Ibiporã. Boletim Informativo, v. 3, n. 5, p. 1-3, 1996.

VIANA, S.M.; TOSETTI, L.L.; ROLLO, L.C.P.; SILVA FILHO, D.F. Valoração monetária: Pesquisas em floresta urbana. Revista da Sociedade Brasileira de Arborização Urbana, v. 7, n. 1, p. 76-88, 2012.

VITO. PROBA-V Mission Exploitation Platform. 2021. Disponível em: <https://proba-vmep.esa.int/applications/time-series-viewer/app/app.html>. Acesso em: 04 jul. 2021.

WANG, X.; YAO, J.; YU, S.; MIAO, C.; CHEN, W.; HE, X. Street trees in a Chinese forest city: Structure, benefits and costs. Sustainability, v. 10, n. 3, p. 674, 2018.

WATSON, D.J. Comparative physiological studies on growth of field crops: I. Variation in net assimilation rate and leaf area between species and varieties, and within and between years. Annals of Botany, v. 11, p. 41-76, 1947.

WORLD WILDLIFE FUND (WWF). Living Planet Report 2020. Gland: WWF, 2020. 159 p. 


\section{Flávio Henrique Mendes}

Escola Superior de Agricultura "Luiz de Queiroz" (ESALQ), Universidade de São Paulo (USP)

friquemendes@usp.br

https://orcid.org/0000-0002-7628-4850

\section{Hugo Romero}

Facultad de Arquitectura y Urbanismo (FAU), Universidad de Chile (UChile) hromero@uchilefau.cl

https://orcid.org/0000-0002-1005-0269

\section{António Manuel Saraiva Lopes}

Instituto de Geografia e Ordenamento do Território (IGOT), Universidade de Lisboa (UL)

antonio.lopes@campus.ul.pt

https://orcid.org/0000-0002-9357-7639

\section{Maria de Assunção Ribeiro Franco}

Faculdade de Arquitetura e Urbanismo (FAU), Universidade de São Paulo (USP) mariafranco@usp.br

https://orcid.org/0000-0001-9679-8552

\section{Demóstenes Ferreira da Silva Filho}

Escola Superior de Agricultura "Luiz de Queiroz" (ESALQ), Universidade de São Paulo (USP)

dfilho@usp.br

http://orcid.org/0000-0001-8674-8041

Recebido em: 27/07/2021.

Aceito em: 04/12/2021. 